\title{
El catálogo digital de las monedas antiguas de la Península Ibérica
}

\section{The Digital Catalogue of the Ancient Coins of the Iberian Peninsula}

\section{Manuel Gozalbes $^{\mathrm{a}}$, Juan Francisco Onielfa Veneros ${ }^{\mathrm{b}}$, Alejandro Peña Carbonell ${ }^{\mathrm{b}}$ y Pere} Pau Ripollès ${ }^{c}$,

${ }^{\mathrm{a}}$ Museu de Prehistòria de València, manuel.gozalbes@dival.es, ${ }^{b}$ Render SL, alex@render.es, paco@render.es, ${ }^{\mathrm{c}}$ Departament de Prehistòria, Arqueologia i Història Antiga, Universitat de València, ripolles@uv.es

\begin{abstract}
Resumen
La web monedaiberica.org es el catálogo digital de las monedas antiguas de la Península Ibérica y del sur de Francia acuñadas por más de 200 ciudades entre los siglos VI y I a.C. Su publicación se produce en el marco del proyecto ARCH (Ancient Coinages as Related Cultural Heritage). El resultado es una importante web de libre acceso donde se ofrecen los resultados de un prolongado trabajo de recopilación e investigación desarrollado durante cuatro décadas. El catálogo incluye 4.000 tipos monetarios de las culturas griega, púnica, ibérica, celtibérica, vascona y lusitana. El proyecto reúne más de 100.000 monedas con imágenes, procedentes de museos, subastas públicas y colecciones particulares. El sistema incluye 7.000 publicaciones y 40.000 citas bibliográficas.
\end{abstract}

Los contenidos se organizan mediante un gestor de contenidos llamado Numisdata, basado en Dédalo, un gestor de código abierto. Se trata de una aplicación web que permite el trabajo en entornos colaborativos y con potentes capacidades para la gestión de idiomas, usuarios y proyectos. El sistema registra a finales de 2020 un total de 575.000 registros, 8.000 términos de tesauro, 30.000.000 de relaciones entre registros y 8.000.000 de acciones de actividad. La página web proporciona enlaces a otros proyectos nacionales e internacionales, principalmente arqueológicos y bibliográficos, e incluye URIs como enlaces permanentes para sus contenidos.

Palabras clave: numismática, arqueología, sistema gestión contenidos, aplicación web, catálogo, tesauros, enlaces.

\footnotetext{
Abstract

The website monedaiberica.org is the digital catalogue of the Ancient coins of the Iberian Peninsula and the South of France minted by more than 200 cities between the 6th and 1st centuries BC. It is published within the framework of the ARCH project (Ancient Coinages as Related Cultural Heritage). The result
} 
is an important free access website that offers the results of a long compilation and research work carried out for over four decades. The catalogue includes 4,000 coin types from the Greek, Punic, Iberian, Celtiberian, Vasconian and Lusitanian cultures. The project gathers over 100,000 coins with images, from important museums, public auctions and private collections. The system includes 7,000 publications and 40,000 bibliographic citations.

The contents are managed with a system called Numisdata, based on Dédalo, an open source tool. It is a web application that allows to work in collaborative environments and that offers powerful capabilities for managing languages, users and projects. By the end of 2020, the system registers a total of 575,000 records, 8,000 thesaurus terms, 30,000,000 relationships between records and 8,000,000 activity actions. The website provides links to other national and international projects, mainly archaeological and bibliographic, and includes URIs as permanent links for its contents.

Keywords: numismatics, archaeology, content management system 


\section{Introducción}

\section{1. El Patrimonio numismático antiguo de la Península Ibérica}

Las monedas han determinado la historia de la Humanidad. Estos pequeños objetos metálicos han servido de forma cotidiana para comerciar, ahorrar o medir el valor de bienes y servicios. La base de las economías monetarias tradicionales ha reposado sobre estas piezas artesanales, producidas en serie y que perviven como valiosa expresión simbólica de aquellas sociedades que las acuñaron. Representan una síntesis artística de culturas extinguidas, donde fueron símbolos tangibles del poder, objetos codiciados y soportes publicitarios de gran impacto. Sus meditados diseños contribuyeron a modelar las creencias de aquellas gentes, su cosmovisión, en una medida que hoy día resulta difícil de comprender.

El legado numismático de las culturas antiguas de la Península Ibérica es de enorme importancia. Las monedas que fabricaron son una fuente primaria de información sobre las sociedades que habitaron la Península Ibérica entre los siglos VI y I a.C. No menos de 220 ciudades acuñaron su propia moneda, poniendo en circulación más de 4.000 variantes tipológicas, vinculadas a diferentes tradiciones culturales como la griega, púnica, ibérica, celtibérica, sur-occidental o latina. Son los únicos documentos oficiales que se conservan de ciudades que desaparecieron en muchos casos. Sus diseños monetarios proporcionan un vasto repertorio relativo a las creencias de aquellas culturas, aunque sus figuras, objetos, símbolos y leyendas resulten de difícil comprensión y, en ocasiones, constituyan verdaderos enigmas.

La disciplina Numismática ha publicado tradicionalmente catálogos de tipos monetarios que han servido como obras de referencia sobre las producciones de las diferentes épocas. En el caso de las series antiguas de la Península Ibérica los catálogos más importantes en el último siglo han sido obra de Antonio Vives y de Leandro Villaronga (Vives 1924-1926; Villaronga 1994; Villaronga y Benages 2011). Estos catálogos tienen un valor inmenso, pero sufren algunas limitaciones derivadas de su condición de obras impresas, pues solo pueden ilustrar un ejemplar de cada tipo y las referencias de los índices son limitadas. Además, sus ilustraciones no siempre permiten apreciar los detalles de las monedas. Esto es comprensible en un contexto editorial condicionado por el uso de fotografías en blanco y negro, de tamaño reducido y de calidades muy diversas. La revolución de la fotografía digital significó que los trabajos de documentación gráfica pasaron a ser asumibles y asequibles, produciendo un crecimiento exponencial de los ficheros de trabajo. Esto ha supuesto un cambio decisivo para la disciplina, ya que las imágenes constituyen la base de cualquier catálogo numismático.

El reciente desarrollo de los sistemas de gestión de conocimiento también ha permitido alcanzar unos estándares muy exigentes que hacen posible crear grandes catálogos digitales con filtros que permiten realizar consultas dinámicas y personalizadas. Este contexto tecnológico combinado con la normalización de imágenes digitales de una calidad sin precedentes, ha provocado un vuelco en el ámbito de los catálogos numismáticos (Granados et al. 2019). Los investigadores deben asumir que, actualmente, el único camino razonable a 
seguir para crear estas obras de referencia pasa por su publicación como catálogos web accesibles sin restricciones.

\subsection{La formación de un catálogo de moneda ibérica: de lo analógico a lo digital}

Hacia 1980, Pere Pau Ripollès comenzó a formar un archivo de monedas antiguas de la Península Ibérica con fotografías montadas en fichas de cartulina. Dicho archivo proporcionaba las bases necesarias para disponer de un criterio sólido en relación con los tipos monetarios existentes. Este fichero tradicional, cuidado y mantenido durante cerca de 25 años reunía en el momento de su cierre alrededor de 20.000 monedas procedentes de subastas y colecciones. El cambio de marco tecnológico, llevó en 2006 a crear en paralelo un archivo de imágenes digitales y una base de datos con CFileMaker para registrar los datos de las mismas.

En el año 2014 Pere Pau Ripollès se incorporó a la comunidad internacional de investigadores cuyo cometido era trabajar en el catálogo $O G C$ de las emisiones griegas antiguas, donde se incluían las monedas antiguas la Península Ibérica (Ripollès y Gozalbes 2016, 747-749). Había que establecer la terminología numismática de referencia en diferentes idiomas para el portal nomisma.org. La reunión «The New Landscape of Ancient Numismatics», celebrada en París en abril de 2014, permitió reflexionar sobre los proyectos activos de numismática romana y sirvió como presentación oficial del corpus web de moneda griega (International Numismatic e-Newsletter 17, julio de 2014, 13-15). Aquel encuentro supuso un punto de inflexión en relación con la decisión de crear un catálogo digital de las monedas antiguas de la Península Ibérica. Dos años más tarde durante la reunión de Madrid, «Colecciones museísticas en línea - La numismática como ejemplo», Pere Pau Ripollès expuso por vez primera la intención de crear un catálogo digital de moneda ibérica en el marco del Online Greek Corpus (OGC).

En mayo de 2017 tuvo lugar el 6th meeting ECFN/nomisma.org en Copenhague. Durante un encuentro informal celebrado fuera del programa se acordó presentar un proyecto en la Digital Heritage Joint call que formaba parte de la convocatoria europea Joint Programming Initiative on Cultural Heritage (2018-2021). El proyecto bautizado como ARCH, Ancient Coinages as Related Cultural Heritage fue concedido en julio de 2018 y contemplaba la creación del catálogo web monedaiberica.org (MIB). Los miembros del proyecto son la Universidad de Oxford, la Biblioteca Nacional de Francia y la Universitat de València. El equipo español, se encuentra formado por el Departament de Prehistòria, Arqueologia i Història Antiga (Universitat de València) y el Museu de Prehistòria de València (Diputación de València), y tiene como principal objetivo el desarrollo de MIB, la base de conocimiento para la documentación, archivo, estudio, catalogación y difusión del patrimonio numismático antiguo de la Península Ibérica y del sur de la Galia. El nombre moneda ibérica se utiliza con un sentido geográfico, ya que se incluyen las acunaciones realizadas en la Península entre los 
siglos VI y I a.C. por griegos, púnicos/cartagineses, iberos, celtíberos, vascones, lusitanos y latinos (Ripollès 2013 y 2017).

La aplicación DÉDALO, nacida en 1998 y concebida desde su origen para la gestión de patrimonio cultural, había sido utilizada por miembros del equipo tras haber sido implementada en el Museu de Prehistòria de València en el año 2015 (Sánchez et al. 2018, 373-379). Su utilización en dicho contexto permitió comprobar de primera mano su enorme potencial para diseñar un catálogo de numismática estructurado en múltiples secciones relacionadas, pensado para el trabajo colaborativo y con un control directo de la publicación de los contenidos en web. En el año 2016 se comenzó a desarrollar un modelo de datos adaptado para la gestión y publicación de catálogos numismáticos que se bautizó con el nombre de Numisdata (figura 1).

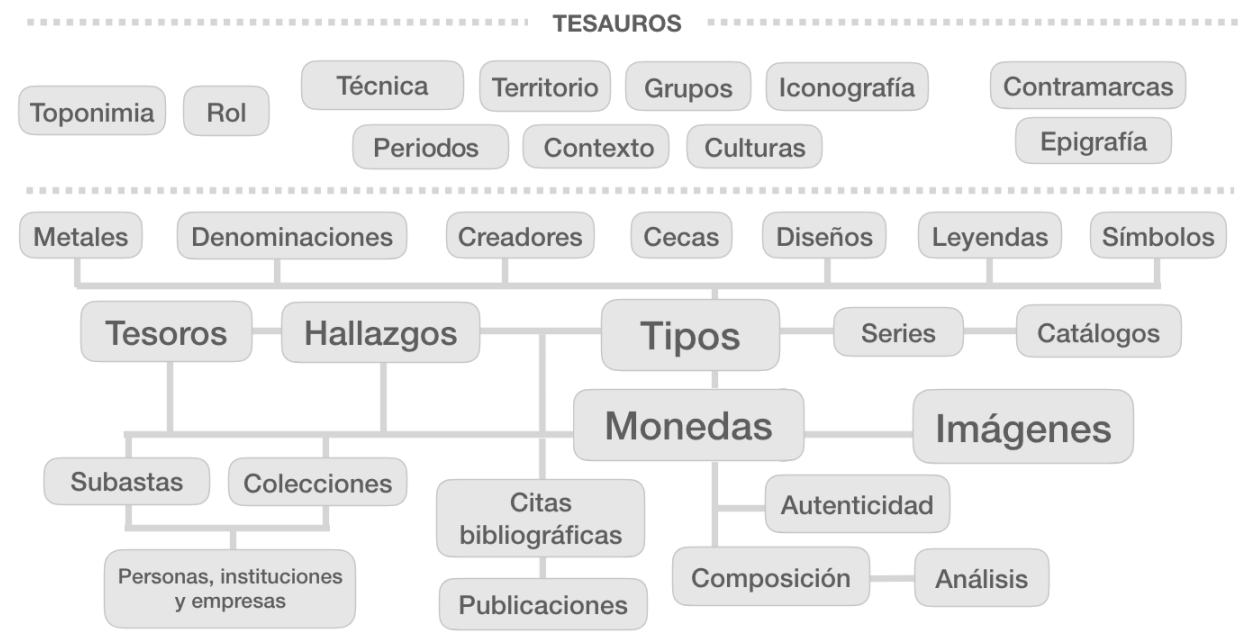

Fig. 1 Esquema de la estructura de secciones de Numisdata

Dicho modelo de datos se fue ajustando con los contenidos de dos catálogos web de menor envergadura, uno de hallazgos monetarios de Cerdeña (numisdata.org/sardinia; Ripollès et al., en prensa) y otro de la importante colección Vidal Valle de moneda valenciana (numisdata.org/vidalvalle; Ripollès et al. 2020). A finales de 2017 se puso en marcha la instalación de MIB y se comenzaron a probar los contenidos para el catálogo monedaiberica.org. La concesión del proyecto $\mathrm{ARCH}$ al año siguiente, proporcionó los recursos que contribuyeron a su lanzamiento. Realmente la financiación aportada por esta convocatoria no paga lo que cuesta una iniciativa de esta envergadura, ni cubre su desarrollo o mantenimiento futuro. Proporciona recursos que facilitan su lanzamiento, pero los 
resultados obtenidos son el fruto del trabajo, tiempo y dinero aportado por un equipo durante décadas. También hay que dejar constancia que el Museu de Prehistòria de València no pudo siquiera postularse como miembro principal del proyecto debido a que el Ministerio de Ciencia, Innovación y Universidades excluye a los museos de dichas convocatorias al no considerarlos como centros de investigación, un criterio que ignora y contradice las funciones establecidas para estos centros por el artículo 59.3 de la Ley 16/1985 de Patrimonio Histórico.

\section{Objetivos}

\subsection{Estructura y contenidos del catálogo de moneda ibérica}

El objetivo de este proyecto de investigación es ordenar la producción monetaria de las ciudades antiguas de la Península Ibérica y el sur de la Galia desde una perspectiva histórica amplia y multidisciplinar. El catálogo numismático de los diferentes tipos producidos entre los siglos VI a.C. y I d.C. debe ocupar el centro del proyecto, acompañado por documentación sobre monedas, tesoros y hallazgos, todo ello avalado por un exhaustivo aparato bibliográfico. El objetivo es articular un gran sistema de conocimiento con múltiples relaciones internas entre sus contenidos. La información debe mostrarse en una página web potente, versátil, clara y atractiva.

Las cecas o ciudades emisoras son el centro del catálogo, que presenta sus producciones ordenadas por tipos y variantes (figura 2). Los tipos monetarios se definen a partir de sus aspectos formales (diseños y leyendas), propiedades físicas (metal y denominación) y de los promedios de sus magnitudes (peso y módulo). La agregación de estas características permite identificar las combinaciones singulares que dan lugar a cada tipo monetario o variante (figura 3). La construcción del catálogo debe realizarse contemplando diversas premisas que garanticen el rigor de la obra:

- Método. Ordenar y agrupar las producciones monetarias definiendo los conceptos de tipo y variante según criterios homogéneos, rigurosos y jerárquicos, superando los modelos tradicionales enumerativos. Es el primer catálogo de moneda ibérica que recurre al concepto variante, necesario para describir aquellas singularidades menores más vinculadas con la fábrica que con la autoridad. Este mismo criterio se aplicó para las variantes de las leyendas de las emisiones provinciales de Hispania (Ripollès 2010).

- Fotografía. Ilustrar el catálogo con imágenes de calidad que tengan fuerza probatoria de los tipos y variantes creadas. Además, cada entrada del catálogo debe estar avalada por las imágenes de todos sus ejemplares conocidos. Esta información nunca ha sido proporcionada por los catálogos precedentes y constituye la base para crear una obra fidedigna.

- Documentación. Contextualizar cada producción monetaria en sus respectivos contextos cívicos y culturales. Proporcionar además documentación exhaustiva de las cecas, tesoros y los lugares de hallazgo de las monedas. 
- Epigrafía. Las monedas antiguas de la Península Ibérica incluyen leyendas que utilizan los signarios griego, púnico, paleohispánico septentrional y meridional, latín y sur-occidental (Velaza 2019), compuestos por numerosos caracteres que no tienen cabida en el sistema Unicode. Para el proyecto de moneda ibérica es necesario desarrollar una solución tecnológica que represente con precisión las leyendas en cualquier navegador y que sea compatible con el sistema internacional Unicode (Ripollès et al., en prensa). El reto es importante porque hasta ahora los catálogos web sólo han empleado glifos del estándar Unicode o imágenes para grafías especiales.

- Cartografía. La localización sobre un mapa de cecas, tesoros y hallazgos resulta de importancia capital como parte del proyecto. Dicha información constituye en muchos casos el indicio más valioso para localizar cecas cuyo único rastro actual es la dispersión de sus emisiones monetarias.

- Bibliografía. La investigación se fundamenta en las aportaciones de una larga tradición académica, por lo tanto las publicaciones deben ser un apartado clave del proyecto. La incorporación de enlaces externos a las publicaciones cuyo contenido se ofrezca en abierto enriquecerá de forma notable los contenidos.

- URIs. Los contenidos del sistema deben incorporar enlaces permanentes o URIs. Estos enlaces de carácter longevo contribuyen a crear potentes redes digitales que integran con fluidez los contenidos de fuentes diversas, proporcionando al usuario recursos exhaustivos sobre las materias en cuestión. La incorporación del modelo Linked Open Data permite explotar todas las posibilidades que ofrecen los datos enlazados para su máxima difusión y plena integración con otros proyectos de humanidades digitales (Meadows y Gruber 2014). 


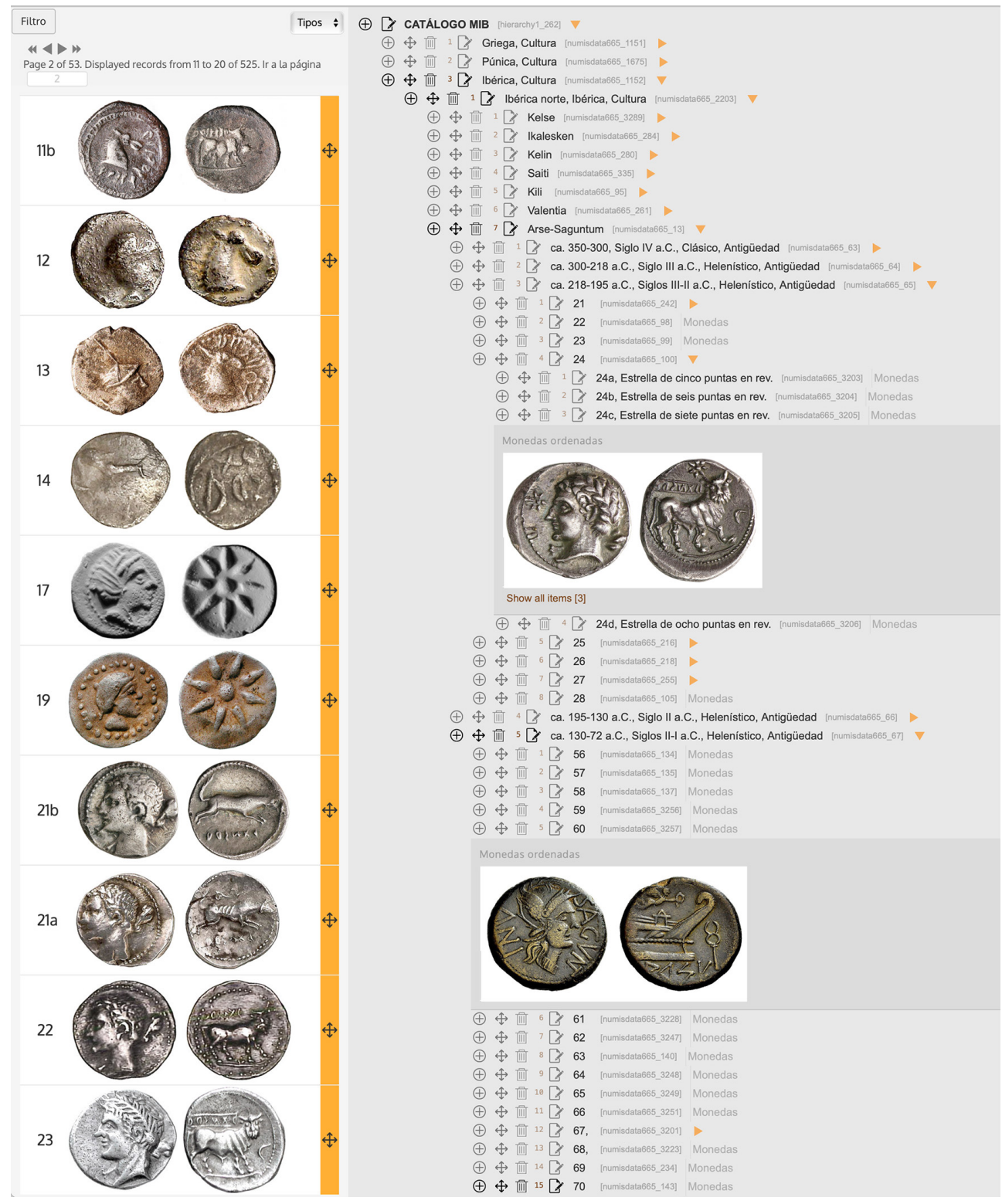

Fig. 2 Catálogo de tipos de Arse-Saguntum en el sistema de gestión Dédalo/Numisdata 


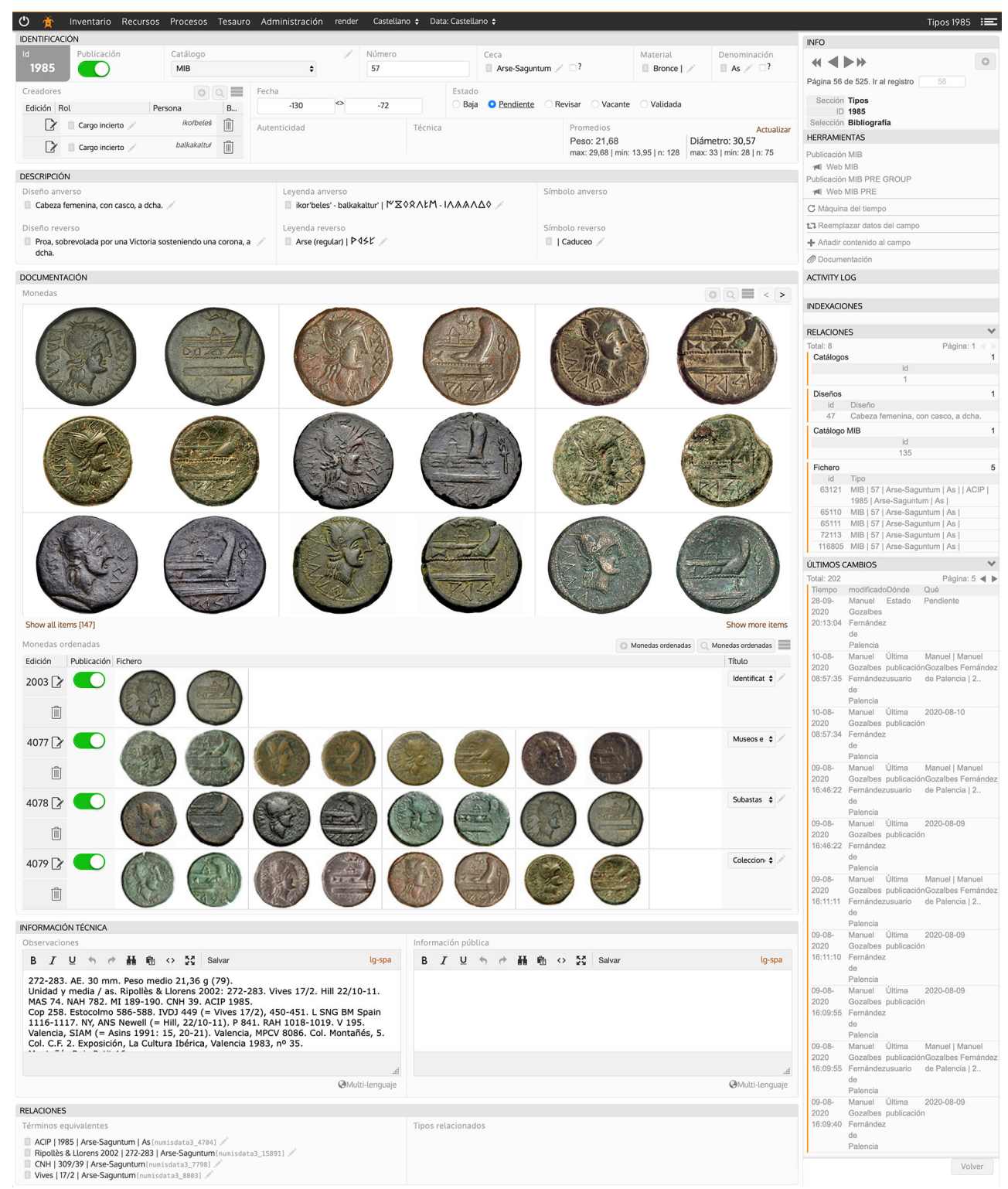

Figura 3. Ficha de un tipo monetario de Arse-Saguntum en el sistema de gestión Dédalo/Numisdata. 


\section{Desarrollo de la innovación}

\subsection{La aplicación Dédalo para crear un catálogo de referencia}

El proyecto digital monedaiberica.org ha sido concebido y desarrollado con el sistema de gestión de patrimonio cultural Dédalo (dedalo.dev). Su dilatada trayectoria proporciona un entorno muy versátil y robusto para grandes proyectos y el trabajo en equipo. La generación dentro de Dédalo de una ontología numismática (estructuración de datos), se inició a mediados de 2016 y recibió el nombre de Numisdata. La instalación para comenzar a trabajar en el catálogo de moneda ibérica se puso en funcionamiento en enero de 2017.

El objetivo principal de Dédalo es la estructuración de contenidos pertenecientes al patrimonio cultural material e inmaterial. La información se organiza internamente en secciones (tablas) y componentes (campos) que pueden ser vinculados entre ellos. En Dédalo las referencias cruzadas de valores entre fichas funcionan mediante localizadores, un sistema de enlaces internos que actualiza automáticamente las fichas de destino cuando se cambia el valor original. Los contenidos se estructuran por lo tanto como un gran entramado dinámico de registros relacionados, donde las modificaciones de valores tienen efecto inmediato y automático sobre todas sus apariciones en el sistema.

La arquitectura Numisdata proporciona una herramienta de investigación estándar para la disciplina Numismática que también permite la publicación web de los contenidos (figura 4). El trabajo se realiza sobre el modelo de datos JSON de Dédalo y se separa la gestión interna (NoSQL en PostgreSQL) de la visualización pública de los contenidos (SQL en MySQL), lo que aporta escalabilidad al sistema y genera un espacio de trabajo seguro y controlable. Hay que destacar el control que los usuarios tienen sobre la publicación de cada una de las fichas accesibles desde la web. Para publicar contenidos basta con activar el selector de publicación de cada ficha y hacer click sobre el botón de envío, lo que produce la publicación directa e inmediata de los contenidos seleccionados.

\subsection{Entorno de trabajo}

Dédalo ofrece diferentes características nativas que enriquecen de forma notable el entorno de trabajo. El sistema tiene capacidad para trabajar con múltiples idiomas, proyectos, usuarios, tesauros, catálogos, recursos gráficos y documentales, versiones y bibliografías, características todas ellas que le otorgan una notable potencia, seguridad y versatilidad.

- Idiomas. La estructura original permite traducciones ilimitadas de los contenidos a cualquier idioma. Cada uno de los campos existentes puede albergar todos los idiomas que se decidan configurar, pero la interfaz solo muestra los datos en el idioma de trabajo elegido. Por el momento los contenidos principales de MIB, generalmente los textos cortos en castellano, se encuentran traducidos al inglés, francés, italiano, portugués y valenciano. 
- Usuarios. Hasta la fecha 40 personas, entre las que se incluyen investigadores, personal contratado, alumnos en prácticas, colaboradores coleccionistas y aficionados, han contribuido a los contenidos de MIB. El sistema permite generar perfiles para asignar a cada uno de ellos un acceso personalizado a las diferentes secciones y componentes. Los perfiles también sirven para habilitar diferentes herramientas de trabajo; importación de imágenes, máquina del tiempo, carga de archivos, acceso a ficheros, importación, exportación, transcripciones, etc.

- Proyectos. Los registros se pueden asignar a proyectos y el perfil de los usuarios se configura con permisos de acceso a dichos proyectos. En ocasiones, por comodidad o por seguridad, puede resultar ventajoso que los editores de contenidos accedan sólo a una selección de registros. En el caso de MIB se han creado siete proyectos que filtran los contenidos para diferentes tipos de usuarios.

- Versiones. La herramienta «máquina del tiempo» genera un registro de cambios que permite recuperar campo a campo cualquier versión previa de los datos, aportando un elevado grado de confiabilidad en un sistema de naturaleza colaborativa. Además, permite la recuperación de registros eliminados. Ambas funcionalidades han resultado de gran utilidad en el proceso de creación de contenidos de MIB. Por otro lado, este minucioso registro histórico de cambios identifica a los autores y editores de las fichas, información que resulta útil para los créditos de la web. 


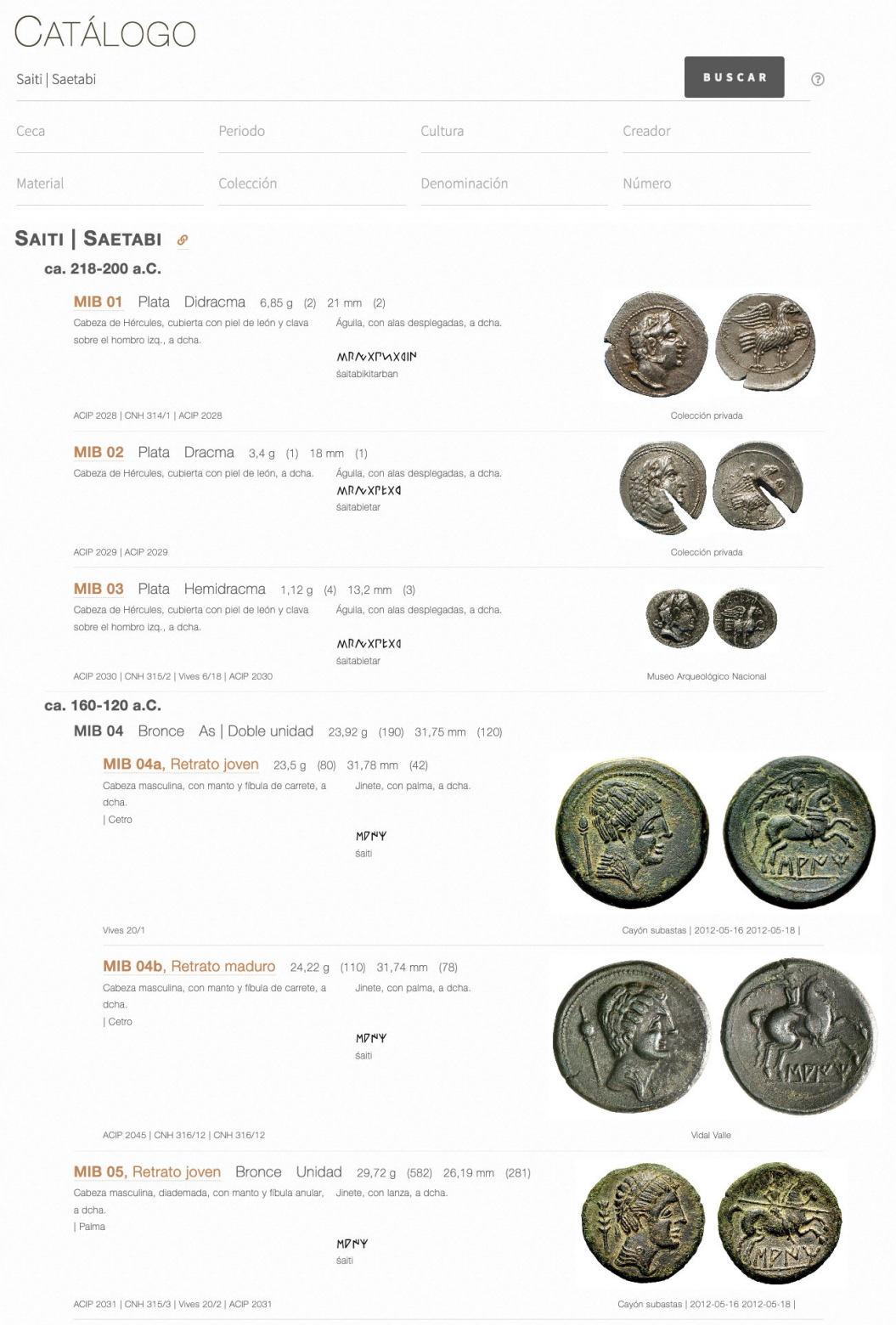

Fig. 4 Catálogo de tipos de la ceca de Saiti en la web monedaiberica.org

- Tesauros. Una parte esencial de este sistema son los tesauros, conjuntos de términos que comparten un modelo de ficha, que se pueden organizar de forma jerárquica y que admiten relaciones cruzadas múltiples. Las equivalencias entre fichas de tipos, por ejemplo, resultan de gran utilidad en un catálogo numismático que debe marcar las correspondencias con los 
trabajos precedentes. Cualquier registro puede incorporar términos de cualquier tesauro, un recurso que proporciona a todos los contenidos del sistema una indexación muy potente. En la actualidad MIB dispone de tesauros de diferentes tipologías cuyos conceptos se amplían y modifican de forma constante:

Toponímicos. 249 países estructurados con los tld2 (top-level domain) de ISO 3166-2 de los cuales 177 cuentan con su toponimia oficial disponible al completo (p. ej. aldeas, pedanías, municipios, comarcas, provincias o comunidades autónomas en el caso de España). Esta información resulta clave para georreferenciar cecas, tesoros o hallazgos de una forma normalizada.

Temáticos. El proyecto MIB incluye con esta tipología tesauros relativos a grupos numismáticos, descriptores onomásticos, iconografías, materiales, temas, toponimia histórica, períodos, culturas, hallazgos, contextos de hallazgo, técnica y objetos. Todos ellos permiten una potente ordenación e indexación de los contenidos. Por ejemplo, un tesoro puede ser indexado desde un solo campo mediante diferentes conceptos (período, territorio o contexto de hallazgo), o los tipos pueden buscarse por un agrupador como «animales», término implícito, pero que no aparece como tal en las descripciones de las monedas.

Semánticos. En este caso se ha desarrollado un tesauro de los roles desempeñados por todas aquellas personas vinculadas con la fabricación de moneda, desde los diferentes tipos de autoridades hasta los artesanos.

Epigráficos. Inicialmente se disponía de 2.177 glifos procedentes de fuentes tipográficas de creación propia que se convirtieron al formato SVG. Con estos archivos se han creado tesauros epigráficos con los glifos estructurados y definidos de griego, púnico, latín, paleohispánico oriental, meridional y sur-occidental (Ripollès et al., en prensa). Además se han incorporado dos tesauros independientes que proporcionan símbolos y contramarcas. El sistema permite además transcribir leyendas combinando caracteres normalizados Unicode con las grafías ibéricas.

Catalográficos. Dédalo/Numisdata permite crear un número ilimitado de catálogos, organizando cualquier contenido del sistema en jerarquías decididas por los investigadores. Los contenidos se pueden ordenar y repetir libremente en modo árbol en cuantos catálogos diferentes resulte necesario. Los contenidos existentes que ahora se publican a través del catálogo monedaiberica.org podrían utilizarse, por ejemplo, para realizar catálogos monográficos de cualquier ceca con las piezas ordenadas por cuños.

Sitios web. Este tesauro tiene el propósito de generar la estructura de los menús web y los textos de presentación de cada uno de los apartados.

Dédalo también incluye herramientas para etiquetar archivos multimedia, una potente manera de vincular cualquier concepto numismático con partes seleccionadas de las imágenes o de los archivos en PDF. Además, el sistema tiene herramientas para la gestión de datos georreferenciados, publicaciones, gestión de recursos (video, imágenes y pdf), exportación e importación de tablas, etc. 


\subsection{Publicación y Open API}

En el modelo de publicación de contenidos de Dédalo, el acceso público a los datos, genera un entorno separado del espacio de trabajo. Cada publicación es una copia de los datos generada en un momento concreto. De igual forma que se genera una versión cuando imprimimos físicamente un catálogo, la publicación en Dédalo fija los datos publicados. En un catálogo donde está previsto que se produzcan actualizaciones, esta configuración es clave ya que se ha de poder referir al estado en el que se presentaba el catálogo en un momento concreto.

La iniciativa Open API es el modelo que sigue Dédalo para el acceso público de los datos. La idea va más allá de la mera generación de URIs estables, ya que permite la conexión entre archivos abstrayendo los sistemas de información. El API REST de Dédalo ofrece herramientas de obtención búsqueda, ordenación y selección de la información permitiendo enlazar las colecciones a través un interfaz JSON. Nuestra visión es que la web semántica ha de avanzar en esta dirección.

Este modelo de comunicación entre diferentes sistemas a través de API público se utiliza en MIB para integrar la base bibliográfica de Zenon (Deutsches Archäologisches Institut). Al realizar una cita bibliográfica en MIB se puede consultar la bibliografía de Zenon desde dentro de Numisdata; solo hay que buscar y seleccionar el resultado que queda enlazado y se actualiza automáticamente, cuando la información de Zenon sufre modificaciones.

\subsection{Datos en constante crecimiento}

La cantidad de información que actualmente gestiona el sistema es importante (2/2021). Se debe tener presente que la sección monedas es la que presenta mayor potencial de crecimiento futuro, mientras que otras como cecas o tipos, se actualizarán en el futuro a un ritmo muy inferior:

- Tipos. El sistema incluye un total de 18.300 fichas de tipos. Entre ellos alrededor de 4.000 tipos y variantes pertenecen a MIB, mientras que el resto corresponden a otros catálogos o monografías de cecas. En este contexto resulta de gran utilidad el reconocimiento automático y cruzado de equivalencias entre tipos que realiza el sistema. En una ficha de tipo MIB, se visualizan las monedas catalogadas con otras obras cuyos tipos se hayan establecido como equivalentes de la misma. En un modelo de ficha ya consolidado, una aportación novedosa y de gran utilidad es el campo clave donde se explica de forma concisa la singularidad de cada tipo.

- Monedas. Inicialmente se incorporaron en la sección fichero los 58.369 registros del fichero digital en CFileMaker con sus respectivas imágenes. Las fichas de papel se incluyeron con posterioridad y progresivamente, tras un prolongado proceso que incluyó su digitalización, ordenación, selección, procesado de imágenes, importación e introducción manual de los 
datos. El fichero de monedas está formado en la actualidad por 139.000 registros, de los cuales unos 100.000 proporcionan la base documental para el proyecto MIB, mientras que los restantes corresponden a las series hispanas de época imperial y a monedas fabricadas en otros lugares, pero que circularon junto con las series ibéricas. Dichas piezas proceden de colecciones públicas, privadas y subastas europeas y americanas de las cuatro últimas décadas. El catálogo incluye monedas de las colecciones más importantes del mundo; Museo Arqueológico Nacional (Madrid), Real Academia de la Historia (Madrid), Instituto Valencia de Don Juan (Madrid), Gabinet Numismatic de Catalunya (Barcelona), Museu de Prehistòria de Valencia (Valencia), British Museum (Londres), Bibliothèque nationale de France (París), American Numismatic Society (Nueva York), Nationalmuseet (Copenhage), Ashmolean Museum (Oxford) o Biblioteca Apostólica (Vaticano) entre otros. Cuando las monedas de estas colecciones se encuentran publicadas con URIs estables, el sistema incorpora dichos enlaces a las fuentes originales.

- Tesoros y hallazgos. El sistema incluye por el momento 4.950 monedas procedentes de 350 tesoros y 7.570 piezas procedentes de hallazgos esporádicos. Las monedas antiguas con procedencia revelan las áreas de circulación de las emisiones monetarias, una información de capital importancia dentro del sistema Numisdata (Peña y Gozalbes, en prensa). Estos contenidos se visualizan sobre una cartografía digital dinámica, una herramienta de enorme valor que permite realizar potentes análisis a partir de búsquedas por múltiples conceptos (figura 5).

- Imágenes. MIB gestiona 322.500 fotografías de monedas, formadas por archivos independientes de anverso y reverso, e imágenes documentales de respaldo de las fichas de papel o capturas de pantalla de subastas. Cabe precisar que dichas imágenes se almacenan en registros vinculados a la ficha de cada moneda y que por tanto pueden incorporar toda la información relacionada con la captura que se precise. 


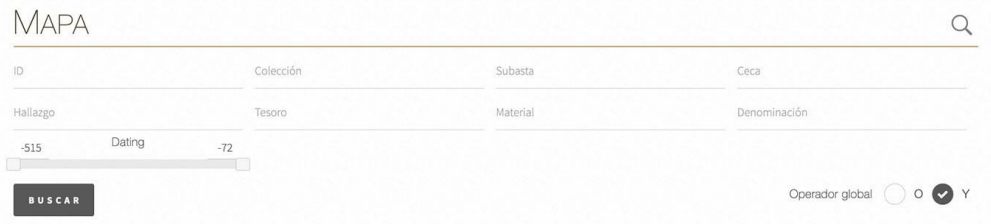
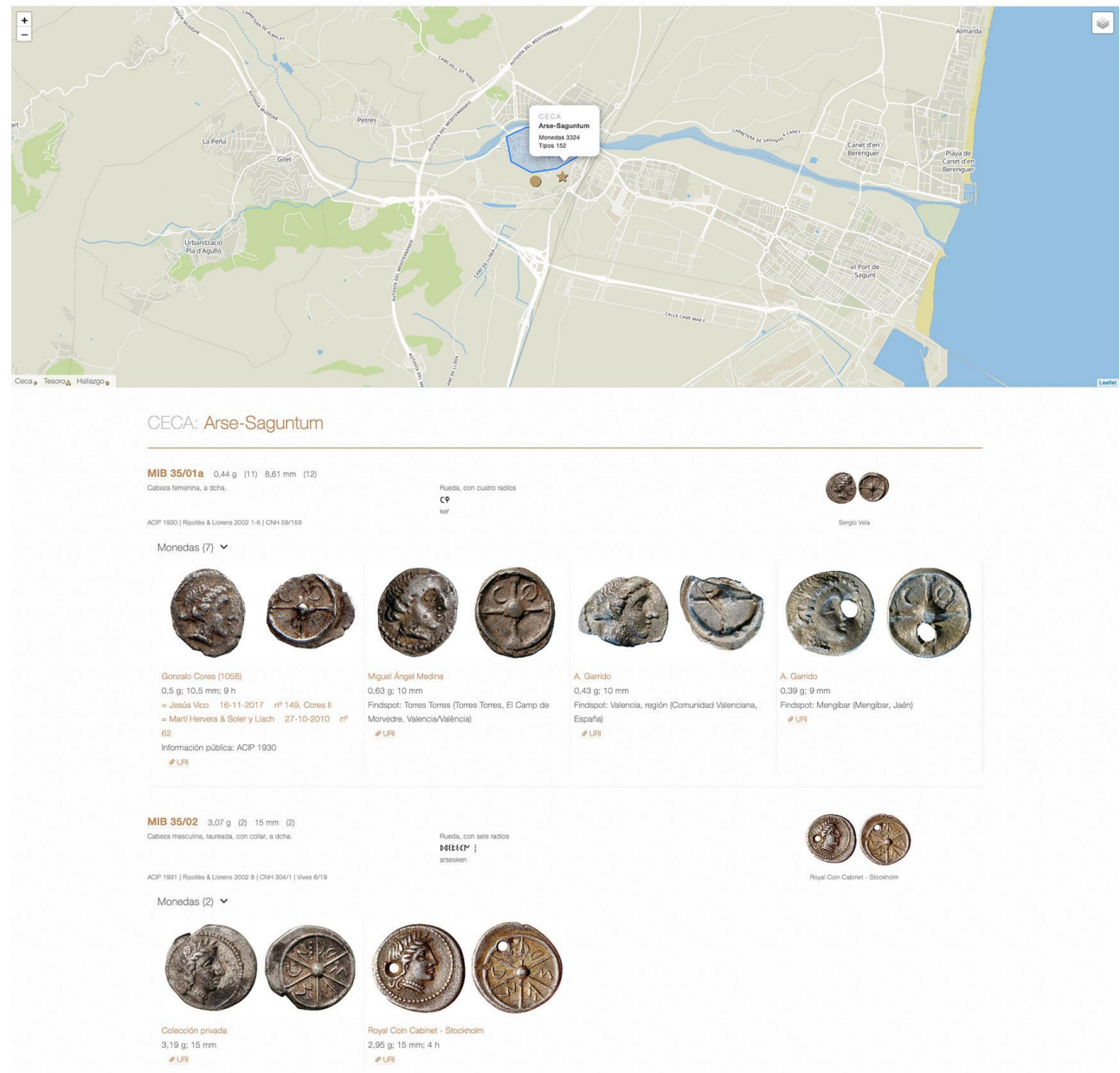

Fig. 5 Mapa web interactivo que muestra hallazgos de monedas de Arse-Saguntum

- Bibliografía. La sección bibliografía incluye 19.547 publicaciones de las que 7.200 se ofrecen en la web monedaiberica.org. El origen de estas fichas se remonta a Numismaster, un fichero de CFileMaker los años 90, que sumaba 15.858 registros cuando sus datos fueron importados a Numisdata. En 2020 se incorporarón 2.750 registros cedidos por Enrique del Río. El sistema comunica directamente con el repositorio Zenon (DAI) lo que permite 
referenciar cualquiera de sus títulos. Además de incorporar un sistema de citas tradicional, el repertorio bibliográfico incluye, cuando es posible, el contenido textual de los archivos pdf para que los usuarios de la web realizar búsquedas que devuelvan un breve extracto de las publicaciones con los términos buscados. Los contenidos de MIB están avalados por 40.000 citas bibliográficas que incorporan referencias concretas o aclaraciones junto a los datos genéricos de la publicación.

\section{Conclusiones}

La magnitud del patrimonio numismático es de tal envergadura que los catálogos digitales exhaustivos y bien estructurados se han convertido en el mejor instrumento para preservar y difundir su legado. La iniciativa monedaiberica.org gestiona mediante Dédalo/Numisata un volumen de información muy notable con el objetivo de documentar en profundidad esta importante parcela de nuestro patrimonio. El proyecto reúne a comienzos de 2021 un total de 575.000 registros, 8.000 términos de tesauro, 30.000 .000 de relaciones entre registros y 8.000.000 de acciones de actividad. La web monedaiberica.org pone a disposición de la sociedad múltiples contenidos y recursos organizados en torno a un catálogo exhaustivo de más de 4.000 tipos monetarios acuñados en la Península Ibérica entre los siglos VI y I a.C. La plataforma es una síntesis de cinco siglos de historia antigua, arqueología, economía, política, epigrafía y arte basada en una exhaustiva documentación ordenada, jerarquizada y contextualizada.

La revolución digital ha puesto a nuestro alcance una cantidad ingente de material que debe ordenarse con rigor. Se han seguido los estándares más exigentes en relación con la normalización y publicación de datos, para que esta plataforma se convierta en un referente ineludible para el conocimiento de la Antigüedad. El nuevo planteamiento digital enriquece de forma espectacular el concepto de catálogo tradicional tanto en forma como en contenidos. Los catálogos monetarios necesitan actualizarse constantemente y por ello la ordenación digital de dicho material permite crear una herramienta de trabajo viva y capaz de incorporar desde un entorno colaborativo todas las novedades que se produzcan. Cada uno de los registros representa un pequeño fragmento, una visión parcial de la historia que cobra sentido y se hace inteligible al integrarse en un contexto de información más amplio.

El trabajo realizado durante décadas por el equipo permite garantizar la exhaustividad del presente corpus y aunque su crecimiento y actualizaciones se prevén inagotables, no han de alterar la esencia de este proyecto. La tendencia internacional hacia la creación de contenidos digitales cada vez más potentes es imparable. En este contexto, la idea inicial de crear un catálogo de las monedas ibéricas en formato impreso pierde sentido. Los recursos y las rutinas de investigación están sufriendo cambios importantes y si dicha publicación tiene que llegar algún día, será como expresión tangible y abreviada de la obra digital.

Nota 
Este trabajo se ha realizado en el marco del proyecto de investigación ARCH, Ancient Coinages as Related Cultural Heritage. Es un proyecto de $\mathrm{I}+\mathrm{D}+\mathrm{i}$ de Programación Conjunta Internacional, correspondiente al Programa Estatal de I+D+i Orientada a los Retos de la Sociedad. Forma parte del Plan Estatal de Investigación Científica y Técnica y de Innovación 2017-202 (PCI2018-092877) que fue aprobado por el Joint Programming Initiative Cultural Heritage: Digital Heritage Management Group (JPICH DHMG) en diciembre de 2017 y está financiado por el Ministerio de Ciencia, Innovación y Universidades.

\section{Referencias}

Chaves Tristán, F. (2010). "Las amonedaciones hispanas en la Antigüedad", en Andreu Pintado", J., Cabrero Piquero, J., Rodà de Llanza, I. (coords.). Hispania. Las provincias hispanas en el mundo romano. Tarragona: Institut Català d'Arqueologia Clàssica, p. 4797.

Dedalo. Managing Cultural Heritage Archives. <https://dedalo.dev> [Consulta: 26 de febrero 2021]

Granados, P.; Gozalbes, M. y Ripollès, P. P. (2019). "Numismatic catalogues and Digital Humanities". Mikulovské kolejní kabinety pomocných věd historických II, p. 16-31.

Grolinger, K., Higashino, W.A., Tiwari, A. et al. (2013). "Data management in cloud environments: NoSQL and NewSQL data stores". J Cloud Comp 2, 22, p. 1-24. https://doi.org/10.1186/2192-113X-2-22 [Consulta: 26 de febrero 2021]

Iniciative. OpenAPI specification 3.1.0 Released $<$ https://www.openapis.org $>$ [Consulta: 20 de febrero 2021].

La Colección Numismática Vidal Valle. Monedas, medallas y fichas de la colección Reino de Valencia. <https://numisdata.org/vidalvalle/> [Consulta: 3 de febrero 2021]

Meadows, A. y Gruber, E. (2014). "Coinage and Numismatic Methods. A Case Study of Linking a Discipline". ISAW Papers 7.15.

Moneda Ibérica. <https://mib.numisdata.org/v1/> [Consulta: 14 de febrero 2021]

Numisdata Sardinia. $<$ https://numisdata.org/sardinia/> [Consulta: 6 de febrero 2021]

Peña, A. y Gozalbes, M. (en prensa), "El sistema de gestión NUMISDATA y los hallazgos monetarios", en XVI Congreso Nacional de Numismática (Barcelona, 28, 29 y 30 de noviembre de 2018).

Ripollès, P. P. (2010). Las acuñaciones provinciales romanas de Hispania, Madrid: Real Academia de la Historia.

Ripollès, P.P. (2013). Ancient Iberian Coinage. Valencia: DoDiA 2, Museu de Prehistòria de València [http://mupreva.org/pub/853]. [Consulta: 26 de febrero 2021] 
Ripollès, P. P., Frulio, M. y Gozalbes, M. (2021). "I rinvenimenti monetali nel Terralbese nel sito numisdata Sardinia”, en Martín Esquivel,A., Ferrandes, A. F. y Pardini, G. (a cura di), Archeonumismatica. Analisi e studio della moneta da siti e contesti pluristratificati. Workshop Internazionale di Numismatica, 2, Roma: Edizioni Quasar.

Ripollès, P. P., Gozalbes, M., Francés, D. y Sendra, J. A. (2020). "La colección numismática Vidal Valle y su publicación digital", en de Francisco, J. M. y Retamero, F. (eds), Homenaje a Josep Pellicer. Barcelona: Asociación Numismática Española, p. 303-316.

Ripollès, P. P., Gozalbes, M., Peña, A. y Onielfa, J. F. (en prensa). "La representación de las leyendas monetarias en el catálogo monedaiberica.org", en XIII Colóquio sobre Línguas e Culturas Paleo-Hispânicas, 23-26 outubro 2019.

Sánchez, A., Gozalbes, M., Peña, A. y Onielfa, J. F. (2018). "Del papel a la Red. Inventarios y catálogos del Museu de Prehistòria de València". Archivo de Prehistoria Levantina XXXII, p. 357-378.

Strauch, Ch. (2012). NoSQL Databases. University Hochschule der Medien, Stuttgart. https://www.christof-strauch.de/nosqldbs.pdf

The United Nations. Statistic Division. Methodology. $<$ https://unstats.un.org/unsd/methodology/m49/overview> [Consulta: 26 de febrero 2021]

Velaza, J. (2019). "Iberian writing and language”, en Sinner, A. G. y Velaza, J. (eds.), Palaeohispanic Languages \& Epigraphies, Oxford: Oxford University Press, p. 160-197.

Villaronga, L. (1994). Corpus Nummum ante Augusti Aetatem. Madrid: José A. Herrero S.A.

Villaronga, L. y Benages, J. (2011). Ancient Coinge of the Iberian Peninsula. Barcelona: Societat Catalana d'Estudis Numismàtics

Vives, A. (1924-1926). La moneda hispánica. Madrid: Real Academia de la Historia. 